\title{
Trocas gasosas e ciclo fotossintético da figueira 'Roxo de Valinhos'
}

\author{
Gas exchanges and cycle fhotosynthetic in fig tree 'Roxo de Valinhos'
}

\author{
Andréa Carvalho da Silva ${ }^{\mathrm{I}}$ Sarita Leonel ${ }^{\mathrm{I}}$ Adilson Pacheco de Souza $^{\mathrm{II}}$ \\ João Rodrigues Domingos ${ }^{\text {III }}$ Carlos Ducatti ${ }^{\text {IV }}$
}

\section{RESUMO}

No presente trabalho, determinaram-se as trocas gasosas de folhas de figueira 'Roxo de valinhos' e o ciclo fotossintético por meio da relação isotópica ${ }^{12} \mathrm{C} /{ }^{13} \mathrm{C}$. Essas medidas foram realizadas sempre na região mediana das folhas, completamente expandidas e totalmente expostas à radiação solar, no periodo das 09 h00min às $10 \mathrm{~h} 30 \mathrm{~min}$. As folhas fotossinteticamente ativas da figueira apresentaram área

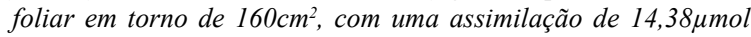
$\mathrm{m}^{-2} \mathrm{~s}^{-1}$ de $\mathrm{CO}_{2}$, cujos valores isotópicos médios no ramo 1 e no 2 são $-28,98 \pm 0,69 \%$ e $-29,28 \pm 0,85 \%$, respectivamente. Com base nos valores da fotossintese máxima e na discriminação isotópica do ${ }^{13} \mathrm{C}$, evidenciou-se que a figueira pode ser considerada uma planta do ciclo fotossintético $C_{3}$.

Palavras-chave: carbono, fotossintese, folhas, isótopos estáveis Ficus carica $L$.

\section{ABSTRACT}

In the present research, it was determined the gas exchange of the 'Roxo de Valinhos' fig tree and the cycle photosynthetic through the isotopic relation ${ }^{12} \mathrm{C} /{ }^{13} \mathrm{C}$. These measures were always carried in the average region of the leaves, completely expanded, entirely displayed to the solar radiation, in the period from 09 h00min to $10 \mathrm{~h} 30 \mathrm{~min}$. The sheets photosynthetic active leaf area had around $160 \mathrm{~cm}^{2}$, with $14.38^{-2} \mathrm{~s}^{-1}$ assimilation $\mathrm{CO}_{2}$, and mean isotopic values in the branch 1 and 2 of $-28.98 \pm 0.69 \%$ and $-29.28 \pm 0,85 \%$, respectively. Based in the values of the maximum photosynthesis and in the discrimination isotopic of the ${ }^{13} \mathrm{C}$, the fig tree can be considered a plant which belongs to photosynthetic $C_{3}$ cycle.

Key words: carbon, photosynthesis, leaves, stable isotopic, Ficus carica $L$.

\section{INTRODUÇÃO}

Originária da Ásia menor e da Síria, na região mediterrânea, a figueira (Ficus carica L.) é uma das mais antigas frutíferas cultivadas no mundo, apresenta excelente adaptação a diferentes climas e é cultivada tanto em regiões subtropicais quentes, como em regiões de clima temperado (DALASTRA et al., 2009). A figueira cultivada possui o nome botânico de Ficus carica L. e pertence à família botânica das Moráceas. O gênero Ficus engloba cerca de mil espécies, sendo muitas dessas espécies largamente usadas como plantas ornamentais.

A colheita brasileira do figo ocorre num período de entressafra da produção da fruta fresca no Hemisfério Norte e nos demais países do Mercosul. Assim, são amplas as possibilidades de exportação, pois o produto brasileiro entra no mercado internacional a partir de dezembro, logo após a safra dos países mediterrâneos (LEONEL \& TECCHIO, 2008). Atualmente, os maiores Estados produtores brasileiros são Rio Grande do Sul, São Paulo e Minas Gerais. Apesar de encontrar condições satisfatórias para o seu desenvolvimento, o cultivo da figueira vem sendo feito de maneira tradicional, sem muitas inovações ou melhorias técnicas (GIACOBBO et al., 2007).

Nas condições brasileiras, a figueira é cultivada com o emprego de uma única cultivar, a 'Roxo de Valinhos', caracterizada por apresentar grande valor

'Departamento de Produção Vegetal, Faculdade de Ciências Agronômicas (FCA), Universidade Estadual Paulista (UNESP), 18610360, Botucatu, SP, Brasil. E-mail: sarinel@fca.unesp.br.*Autor para correspondência.

"Instituto de Ciências Agrárias e Ambientais, Universidade Federal de Mato Grosso (UFMT), Sinop, MT, Brasil.

IIIDepartamento de Botânica, Instituto de Biociências (IB), UNESP, Botucatu, SP, Brasil.

${ }^{\mathrm{IV}}$ Departamento de Física e Biofísica, IB, UNESP, Botucatu, SP, Brasil. 
econômico, rusticidade, elevado vigor e produtividade, além de boa adaptação a podas drásticas. Todavia, dentre os diversos fatores envolvidos na sua produtividade, a fotossíntese é um dos mais determinantes.

A elevação das taxas fotossintéticas depende, dentre outros fatores, do máximo aproveitamento da luz disponível obtido em função da idade fenológica das folhas e por tratos culturais e manejos (BERNARDES, 1987). Nesse processo, as plantas assimilam o $\mathrm{CO}_{2}$ da atmosfera e o reduzem a triose-fosfato, o qual pode então ser usado para a produção de carboidratos, principalmente sacarose e amido.

Toda produção de fitomassa e formação da arquitetura da figueira dependem diretamente da atividade fotossintética, visto que a prática da poda de frutificação é um manejo adotado nos pomares brasileiros, fazendo com a planta apresente uma renovação da parte aérea a cada ciclo produtivo (DALASTRA et al., 2009). Dessa forma, buscar mais informações sobre a fisiologia da figueira é de fundamental importância, sendo as medidas das trocas gasosas uma forma muito utilizada para estudos preliminares.

Dentre as metodologias empregadas na caracterização fotossintética de uma espécie, é destacada a aplicação isotópica em razão da grande confiabilidade nos resultados encontrados (WONG \& ABRAMS, 2003). Os isótopos estáveis do carbono $\left({ }^{12} \mathrm{C}\right.$ e ${ }^{13} \mathrm{C}$ ) tornaram-se uma ferramenta muito útil na pesquisa sobre aspectos relacionados à fisiologia de plantas, uma vez que as razões entre esses dois elementos podem auxiliar diretamente no estudo da fotossíntese, na determinação dos ciclos fotossintéticos, na translocação e na alocação de carbono e estresse hídrico. Indiretamente, servem de base para o melhoramento de plantas tolerantes ao estresse hídrico e as aplicações em trabalhos relacionados a desbaste/poda de plantas, notadamente em fruteiras (EHLERINGER et al., 1993).

Este trabalho teve como objetivos caracterizar as trocas gasosas de folhas da figueira 'Roxo de Valinhos' e determinar o mecanismo do ciclo fotossintético por meio da metodologia isotópica.

\section{MATERIAL E MÉTODOS}

Os experimentos foram realizados em campo, na área experimental do pomar do Departamento de Produção Vegetal e Horticultura da Faculdade de Ciências Agronômicas, FCA/UNESP, campus de Botucatu, São Paulo (SP), localizada na latitude $22^{\circ} 52^{\prime} 47^{\prime \prime}$ S e na longitude $48^{\circ} 25^{\prime} 12^{\prime \prime} \mathrm{W}$, com altitude média de $810 \mathrm{~m}$. Pela classificação de Köppen, o tipo climático predominante no local é o $\mathrm{Cfa}$, caracterizado como temperado quente (mesotérmico), com chuvas no verão e seca no inverno, com precipitação e temperatura média anual de $1530 \mathrm{~mm}$ e $21^{\circ} \mathrm{C}$, respectivamente (CUNHA \& MARTINS, 2009).

As figueiras 'Roxo de Valinhos' estavam instaladas desde 2001, em um Nitossolo Vermelho (EMBRAPA, 2006), com espaçamento de 3x2m. Essas plantas receberam tratos culturais como podas de formação, frutificação e desbrotas com a finalidade de adquirirem a conformação de seis a nove ramos produtivos.

As determinações das trocas gasosas foram realizadas com um medidor portátil de fotossíntese, IRGA, modelo LI-6400 (LI-COR). As medidas foram feitas sempre na região mediana das folhas completamente expandidas, totalmente expostas à radiação solar, no período das $09 \mathrm{~h}$ às $10 \mathrm{~h} 30 \mathrm{~min}$. As seguintes características foram medidas: assimilação líquida de $\mathrm{CO}_{2}\left(\mu \mathrm{mol} \mathrm{m} \mathrm{m}^{-2} \mathrm{~s}^{-1}\right)$; taxa de transpiração nas folhas $\left(\mathrm{mmol} \mathrm{m} \mathrm{m}^{-2} \mathrm{~s}^{-1}\right)$; condutância estomática nas folhas $\left(\mathrm{mol} \mathrm{m} \mathrm{m}^{-2} \mathrm{~s}^{-1}\right)$; concentração de $\mathrm{CO}_{2}$ nos espaços intercelulares $\left(\mathrm{mmol} \mathrm{m}^{-2} \mathrm{~s}^{-1}\right)$ e eficiência do uso da água $\left(\mu \mathrm{mol} \mathrm{mmol}{ }^{-1}\right)$.

Em cinco plantas com quatro ramos cada, foi determinada a área foliar individual das folhas $\left(\mathrm{cm}^{2}\right)$, obedecendo à localização da folha ao longo do ramo (filotaxia chamada de posição, contando a partir da gema apical). Essa avaliação foi realizada por meio do aparelho integrador fotoelétrico modelo (LI-3000, LICOR).

Para a determinação do mecanismo do ciclo fotossintético da figueira, as folhas, as brotações e os frutos, bem como o meristema, foram arrancados e imediatamente mergulhados em nitrogênio líquido $\left(-196^{\circ} \mathrm{C}\right)$. As amostras foram encaminhadas para o Laboratório do Centro de Isótopos Estáveis Ambientais, do Instituto de Biociências da UNESP, Campus de Botucatu, onde foram colocadas em estufas com circulação de ar forçado a $65^{\circ} \mathrm{C}$, por 72 horas, para secagem. Realizou-se a moagem com o moinho criogênico (Spex - Modelo 6700), no qual as amostras foram colocadas em tubos individualizados, imersas em nitrogênio líquido para a obtenção de um material com finíssima granulometria, permitindo uma perfeita homogeneização. O objetivo da finíssima granulometria foi minimizar as diferenças entre repetições (em número de três), em razão da grande sensibilidade e precisão do espectrômetro de massas $( \pm 0,2 \%$ o). Em seguida, foi retirada, de cada amostra, uma alíquota que variou entre 50 e $70 \mu \mathrm{g}$, que foram acondicionadas em cápsulas de 
estanho, com 6mm de altura e $4 \mathrm{~mm}$ de diâmetro (Modelo D1106-Elemental Microanalysis Limetd). Na sequência, as amostras foram colocadas no analisador elemental (Carlo Erba EA 1108 - Fisons, Milão - Itália). Nesse aparelho, por meio da combustão das amostras, foram liberados o $\mathrm{CO}_{2}$ e o $\mathrm{N}_{2}$, e esses gases foram separados na coluna de cromatografia. Em seguida, o $\mathrm{CO}_{2}$ foi transferido para o ConFlo (Finnigan Mat-Alemanha), onde ocorreu o ajuste da altura em volts da amostra e do padrão. Após esse ajuste, a amostra seguiu para o espectrômetro de massas para razões isotópicas (IRMS) (Modelo Delta S - Finnigan Mat - Alemanha), onde a razão ${ }^{13} \mathrm{C} /{ }^{12} \mathrm{C}$ foi determinada e expressa em $\delta \%$, notação relativa ao padrão-PDB do carbono (Cretaceous carbonate fóssil Bellemitella americana, da formação Peedee do Sul da Carolina/USA), conforme metodologia proposta por DUCATTI et al. (2002).

Os dados referentes à filotaxia foram obtidos de 10 plantas com quatro ramos, sendo considerado um delineamento inteiramente casualizado. Esses dados foram submetidos à análise de variância, pelo teste $\mathrm{F}$, $\mathrm{e}$ as diferenças entre médias foram comparadas pelo teste de Tukey, a 5\% de significância, pelo pacote estatístico SAS. Quando significativas, foram analisadas regressões lineares simples com a área foliar $\left(\mathrm{m}^{2}\right)$ considerada como variável independente, sendo os valores médios das trocas gasosas obtidas de outras 10 plantas com quatro ramos inteiramente casualizadas.

\section{RESULTADOS E DISCUSSÃO}

Durante o período em que foram realizadas as avaliações das trocas gasosas, a temperatura do ar oscilou entre 20,37 e $26,18^{\circ} \mathrm{C}$, e a irradiância incidida na superfície variou de 0,254 a $0,704 \mathrm{~W} \mathrm{~m}^{-2}$ (Figura 1). A umidade relativa do ar apresentou valores entre 64,3 e $77,2 \%$, a radiação fotossinteticamente ativa externa variou entre 798 e $1.868 \mu \mathrm{mol}$ fótons $\mathrm{m}^{-2} \mathrm{~s}^{-1} \mathrm{e}$ a radiação fotossinteticamente ativa interna do aparelho média das leituras foi de $1700 \mu \mathrm{mol}$ fótons $\mathrm{m}^{-2} \mathrm{~s}^{-1}$. Em geral, os valores da temperatura da folha estiveram $3,7 \%\left(1,1^{\circ} \mathrm{C}\right)$ acima da temperatura do ar para todos os dias de avaliação (dados não mostrados), corroborando o resultado obtido por NOGUEIRA et al. (1999), que encontraram diferenças de $1^{\circ}$ a $2,5^{\circ} \mathrm{C}$ em folhas de mangabeira expostas ao sol. A variação sazonal das condições do ambiente ao longo do ano pode causar variações significativas nas trocas gasosas em espécies arbóreas (MACHADO et al., 2002). Assim, para estudos com esse enfoque, as folhas devem estar com as mesmas idades, ou então, deve-se procurar avaliar folhas em diferentes estádios dentro das mesmas condições climáticas.

As características avaliadas (taxa de assimilação líquida de $\mathrm{CO}_{2}$, condutância estomática, concentração interna de $\mathrm{CO}_{2}^{2}$, taxa de transpiração e eficiência do uso da água) em diferentes posições no ramo da planta, em folhas de figueira 'Roxo de valinhos', diferiram estaticamente entre si (Tabela 1). Todavia, os

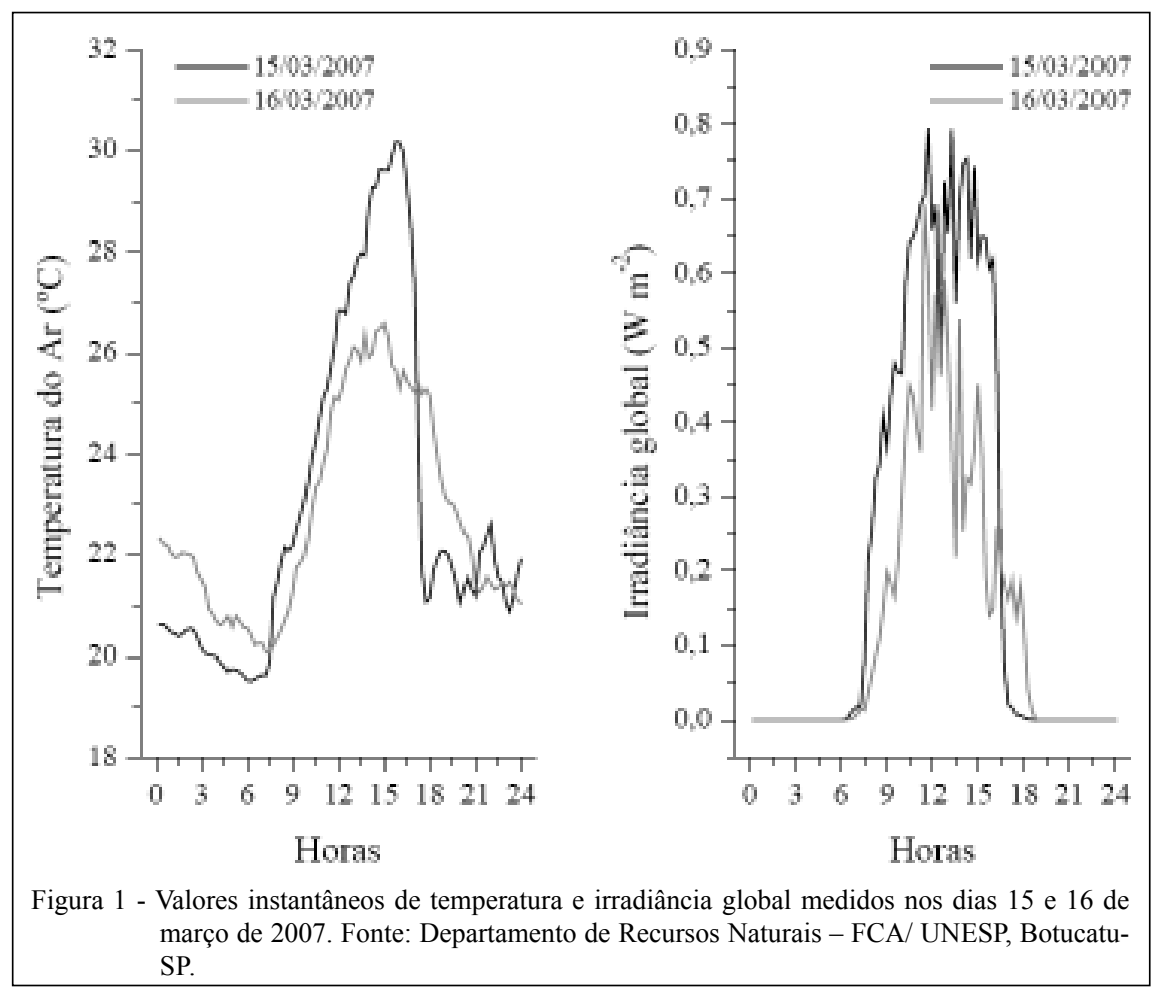

Ciência Rural, v.40, n.6, jun, 2010. 
Tabela 1 - Dados de trocas gasosas de folhas de figueira 'Roxo de Valinhos' em função da filotaxia. Botucatu-SP, 2007.

\begin{tabular}{|c|c|c|c|c|c|}
\hline Posição da Folha & 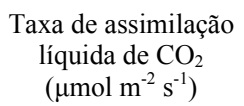 & $\begin{array}{l}\text { Condutância } \\
\text { estomática } \\
\left(\mathrm{mol} \mathrm{m}^{-2} \mathrm{~s}^{-1}\right)\end{array}$ & $\begin{array}{c}\text { Concentração interna } \\
\text { de } \mathrm{CO}_{2} \\
\left(\mathrm{mmol} \mathrm{m}^{-2} \mathrm{~s}^{-1}\right)\end{array}$ & $\begin{array}{l}\text { Taxa de transpiração } \\
\quad\left(\mathrm{mmol} \mathrm{m} \mathrm{m}^{-2} \mathrm{~s}^{-1}\right)\end{array}$ & $\begin{array}{c}\text { Eficiência do uso da } \\
\text { água }\end{array}$ \\
\hline 1 & $-0,370 \mathrm{c}$ & $0,159 \mathrm{~b}$ & $391,58 \mathrm{a}$ & $2,195 \mathrm{~b}$ & $-0,202 b$ \\
\hline 2 & $8,839 \mathrm{~b}$ & $0,316 \mathrm{ab}$ & $308,42 \mathrm{~b}$ & $3,787 \mathrm{ab}$ & $2,867 \mathrm{a}$ \\
\hline 3 & $11,104 \mathrm{ab}$ & $0,389 \mathrm{ab}$ & $301,17 \mathrm{~b}$ & $3,857 \mathrm{ab}$ & $3,344 \mathrm{a}$ \\
\hline 4 & $14,378 \mathrm{a}$ & $0,415 \mathrm{ab}$ & $291,92 \mathrm{~b}$ & $4,226 \mathrm{ab}$ & $3,873 \mathrm{a}$ \\
\hline 5 & $12,832 \mathrm{a}$ & $0,383 \mathrm{ab}$ & $295,58 \mathrm{~b}$ & $4,134 \mathrm{ab}$ & $3,778 \mathrm{a}$ \\
\hline 6 & $14,117 \mathrm{a}$ & $0,427 \mathrm{a}$ & $299,67 \mathrm{~b}$ & $4,413 \mathrm{a}$ & $3,659 \mathrm{a}$ \\
\hline 7 & $13,147 \mathrm{a}$ & $0,407 \mathrm{ab}$ & $306,83 \mathrm{~b}$ & $4,521 \mathrm{a}$ & $3,291 \mathrm{a}$ \\
\hline 8 & $13,839 \mathrm{a}$ & $0,416 \mathrm{ab}$ & $308,5 \mathrm{~b}$ & $4,786 \mathrm{a}$ & $3,250 \mathrm{a}$ \\
\hline $\mathrm{CV} \%$ & 55,01 & 25,77 & 16,39 & 20,47 & 48,63 \\
\hline
\end{tabular}

*Médias não seguidas da mesma letra, na coluna, não diferem pelo Teste de Tukey, a 5\% de probabilidade.

valores dessas variáveis foram semelhantes entre os ramos de uma mesma planta.

Dependendo das condições ambientais, as plantas $\mathrm{C}_{3}$ apresentam atividade fotossintética variando entre $12 \mathrm{e} 25 \mu \mathrm{mol} \mathrm{m} \mathrm{m}^{-2} \mathrm{~s}^{-1}$; as plantas $\mathrm{C} 4$, entre 25 a $40 \mu \mathrm{mol} \mathrm{m} \mathrm{m}^{-2} \mathrm{~s}^{-1}$; e as plantas CAM, entre 2,5 a 7,6 $\mu \mathrm{mol}$ $\mathrm{m}^{-2} \mathrm{~s}^{-1}$ (PIMENTEL, 1998). Por meio dos valores de taxa de assimilação líquida de $\mathrm{CO}_{2}$ obtidos, pode-se relatar que a figueira 'Roxo de Valinhos' é uma planta do tipo $\mathrm{C}_{3}$, corroborando os resultados de TING et al. (1987), ZOTZ et al. (1997) e CAN \& AKSOY (2007). Contudo, os valores médios aqui mensurados podem ser considerados baixos para a espécie Ficus carica., pois PIGÉ et al. (2001), avaliando as características relacionadas à troca de $\mathrm{CO}_{2}$ em folhas e frutos de ramos da figueira com um ano de idade durante a estação primavera-outono, observaram que a taxa de fotossíntese líquida variou de 15 a $20 \mu \mathrm{mol} \mathrm{m}^{-2} \mathrm{~s}^{-1}$.

As folhas jovens apresentaram as menores taxas de assimilação líquida $\mathrm{CO}_{2}$, transpiração e condutância estomática, refletindo diretamente na momentânea ineficiência do uso da água por essas folhas mais novas. Essas folhas apresentaram elevada concentração de $\mathrm{CO}_{2}$ na câmara subestomática, associada à baixa assimilação fotossintética do carbono. A condutância estomática apresentou padrões similares ao da taxa de fotossíntese, sugerindo que a queda da assimilação líquida de $\mathrm{CO}_{2}$ esteja relacionada com o fechamento parcial dos estômatos. As correlações entre a assimilação de $\mathrm{CO}_{2}$ e a condutância estomática podem ser explicadas como uma função da alta concentração de $\mathrm{CO}_{2}$ no sítio de carboxilação, quando ocorre o aumento da condutância estomática, ou então que a fixação de $\mathrm{CO}_{2}$ pode estar restringida pelo metabolismo de carboidrato no citossol da célula e pelos processos supracelulares de transporte de carboidratos, quando existe baixa atividade nas regiões dos drenos de fotoassimilados (BEL, 1992; CAMPOSTRINE \& YAMANISHI, 2001).

Efetivamente, foi observado que folhas com área foliar acima de $60 \mathrm{~cm}^{2}$ começaram a assimilar $\mathrm{CO}_{2} \mathrm{e}$ produzir fotoassimilados (Figura 2a). Por conseguinte, folhas da figueira 'Roxo de Valinhos' apresentaram máxima taxa de assimilação líquida de $\mathrm{CO}_{2}$, quando atingiram $167,7 \mathrm{~cm}^{2}$, valor $2,01 \%$ superior à área foliar média da quarta folha $\left(164,39 \mathrm{~cm}^{2}\right)$. Em média, nas condições ambientais do mês março, em Botucatu, as folhas alcançaram esse valor de área foliar após 26 dias da sua abertura, corroborando as ponderações de PIMENTEL (1998) de que plantas $C_{3}$ têm sua maior produção de fotoassimilados após 21 dias após o inicio do lançamento foliar.

As maiores taxas de transpiração giram em torno de $5,02 \mathrm{mmol} \mathrm{m}^{-2} \mathrm{~s}^{-1}$ para uma área foliar próxima a $0,03 \mathrm{~m} \mathrm{~cm}^{2}$ (Figura 2b); todavia, uma elevada área foliar para uma planta em clima tropical, além de permitir alta interceptação de energia luminosa, significa também uma grande superfície exposta que pode propiciar altas taxas de transpiração. A eficiência do uso da água pelas folhas apresentou comportamento similar à taxa de assimilação líquida de $\mathrm{CO}_{2}$, com maiores eficiências em folhas com área foliar em torno de $180 \mathrm{~cm}^{2}$ (Figura 2d). Segundo SINCLAIR \& HORIE (1989), devem ser selecionadas plantas com maiores áreas específicas unitárias de folhas, ou seja, plantas que apresentem maior peso de folhas por unidade de área, visto que a atividade fotossintética é função do número de cloroplastos, sejam eles dispostos horizontalmente (maior área foliar), sejam dispostos verticalmente (maior espessura e área específica). Folhas com maiores espessuras e com menores áreas de abrangência podem manter boa atividade fotossintética por unidade de área, 

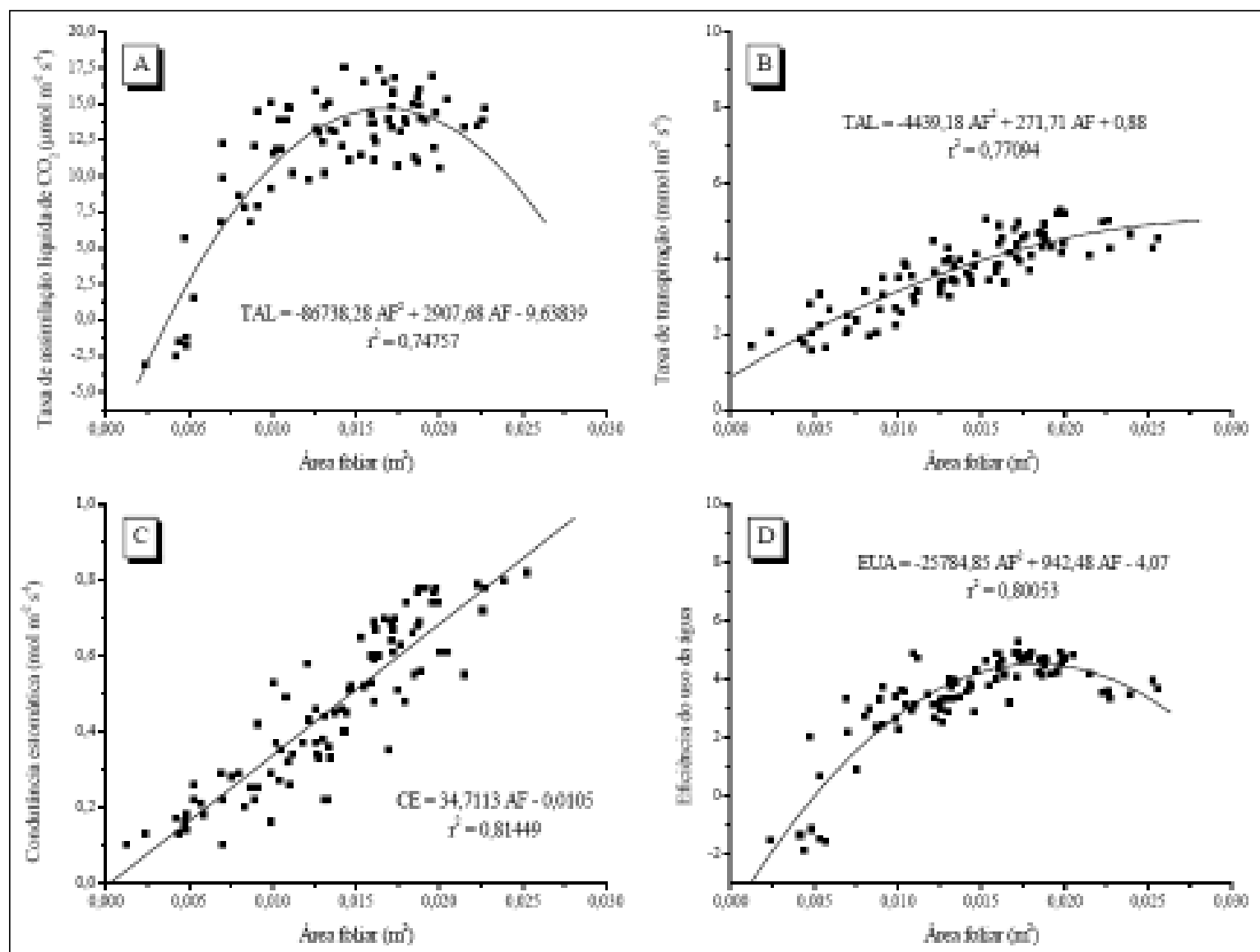

Figura 2 - Taxa de assimilação líquida de CO (a), taxa de transpiração (b), condutância estomática (c) e eficiência do uso da água (d) em função da área foliar de fôlhas de Ficus carica L. Botucatu-SP, 2007.

pois possibilitam a uma maior densidade de cloroplastos.

Outro indicador do processo de assimilação de carbono é a razão isotópica entre ${ }^{13} \mathrm{C} \mathrm{e}{ }^{12} \mathrm{C}$ na matéria seca das plantas, registrada em ppm, tendo por referência um padrão. Segundo LARCHER (2000), atualmente $\mathrm{o}{ }^{13} \mathrm{CO}_{2}$ está sendo encontrado em uma concentração de aproximadamente $1,1 \%$ em relação ao ${ }^{12} \mathrm{CO}_{2}$ na atmosfera. A ocorrência do ${ }^{13} \mathrm{C}$ na massa vegetal é baixa porque, durante a carboxilação, $\mathrm{o}{ }^{12} \mathrm{C}$ é favorecido pelas enzimas. Na comparação de enzimas de plantas $\mathrm{C}_{3}$ e $\mathrm{C}_{4}$ a Rubisco favorece mais fortemente o ${ }^{12} \mathrm{C}$, discriminando mais o ${ }^{13} \mathrm{C}$, quando comparada com a PEP-carboxilase (-28 e -9\%, respectivamente) (FARQUHAR et al., 1989; PIMENTEL, 1998; LARCHER, 2000).

Neste trabalho, foram considerados os ramos originados da mesma seção podada. $\mathrm{O}$ ramo 1 possuía $1,42 \mathrm{~m}$ de comprimento e 35 nós, enquanto o ramo 2 tinha $1,52 \mathrm{~m}$ e 38 nós. As partes novas dos ramos apresentaram valores isotópicos médios de -28,18; 28,23 e -28,40\%o, indicando valores superiores de $\delta^{13} \mathrm{C}$ nas folhas recém-abertas, na gema apical e nos frutos (Tabela 2). As folhas dos nós em que haviam frutos formados apresentaram menores valores isotópicos naturais, mostrando que existe uma discriminação do ${ }^{13} \mathrm{C}$ dessas folhas para a formação dos tecidos de reserva desses frutos.

\section{CONCLUSÃO}

Folhas fotossinteticamente ativas das figueiras 'Roxo de valinhos' são aquelas que assimilam $14,38 \mu \mathrm{mol} \mathrm{m}^{-2} \mathrm{~s}^{-1} \mathrm{de} \mathrm{CO}_{2}$ em uma área de $0,016 \mathrm{~m}^{2}$, sendo seu ciclo fotossintético tipicamente de uma espécie $\mathrm{C} 3$, tanto pelos valores de assimilação líquida de $\mathrm{CO}_{2}$, quanto pelos valores de $\delta^{13} \mathrm{C}$ médios da distribuição natural entre -28,98 e -29,28\%o.

Ciência Rural, v.40, n.6, jun, 2010. 
Tabela 2 - Distribuição natural dos valores de $\delta{ }^{13} \mathrm{C}$ nas partes vegetativas dos ramos da figueira 'Roxo de Valinhos'. FCA/UNESP, Botucatu-SP, 2008.

\begin{tabular}{|c|c|c|c|c|c|c|c|}
\hline \multirow[b]{2}{*}{ Partição da planta } & \multirow[b]{2}{*}{ Posição no ramo } & \multicolumn{3}{|c|}{--------------------Ramo 1------------------ } & \multicolumn{3}{|c|}{---------------------Ramo 2-------------------- } \\
\hline & & $\begin{array}{l}\text { Número de } \\
\text { constituintes }\end{array}$ & $\delta^{13} \mathrm{C}$ Médio & $\begin{array}{l}\text { Desvio } \\
\text { padrão }\end{array}$ & $\begin{array}{l}\text { Número de } \\
\text { constituintes }\end{array}$ & $\delta^{13} \mathrm{C}$ Médio & Desvio padrão \\
\hline Meristema apical & $\mathrm{AP} * *$ & 1 & $-28,62$ & - & 1 & $-28,23$ & - \\
\hline FRA* & $\mathrm{AP}$ & 2 & $-28,18$ & 0,08 & 2 & $-28,63$ & 0,02 \\
\hline Folhas & AP & 8 & $-29,23$ & 0,18 & 12 & $-29,15$ & 0,17 \\
\hline Folhas & MED** & 12 & $-29,62$ & 0,52 & 9 & $-29,92$ & 0,39 \\
\hline Folhas & $\mathrm{MED} / \mathrm{BA}$ & 8 & $-29,87$ & 0,33 & 6 & $-30,41$ & 0,15 \\
\hline Frutos & MED & 7 & $-28,40$ & 0,14 & 4 & $-28,61$ & 0,12 \\
\hline Brotações & AP/MED & - & - & - & 3 & $-29,98$ & 0,20 \\
\hline Média & & & $-28,98 \pm 0,69$ & & & $-29,28 \pm 0,85$ & \\
\hline
\end{tabular}

* FRA: folha recém-aberta; ** Posição no ramo - AP: apical; MED: mediana; BA: basal.

\section{REFERÊNCIAS}

BEL, V.A.J.E. Mechanism of sugar transfer. In: BAKER, N.R.; THOMAS, H. (Ed.). Crop photosynthesis. Amsterdan: Elsevier Sciense, 1992. p.177-211.

BERNARDES, M.S. Fotossíntese no dossel das plantas cultivadas. In: CASTRO, P.R.C. et al. (Eds). Ecofisiologia da produção agrícola. Piracicaba: Associação brasileira para pesquisa da potassa e do fosfato, 1987. p.13-45.

CAN, H.Z.; AKSOY, U. Seasonal and diurnal photosynthetic behaviour of fig (Ficus carica L.) under semi-arid climatic conditions. Acta Agriculturae Scandinavica, v.57, n.4, p.297-306, 2007. Disponível em: <http://dx.doi.org/10.1080/ 09064710600982753>. Acesso em: 10 fev. 2010. doi: 0.1080/ 09064710600982753 .

CAMPOSTRINE, E.; YAMANISHI, O.K. Influence of mechanical root restriction gas-exchange of four papaya genotypes. Revista Brasileira de Fisiologia Vegetal, v.13, n.02, p.129-138, 2001. Disponível em: <http://www.scielo.br/ scielo.ph p s c ript=s ci_arttext \& pid=S $0103-$ $31312001000200002 \& \operatorname{lng}=\mathrm{en} \& \mathrm{nrm}=\mathrm{iso} \& \operatorname{tlng}=\mathrm{en}>$. Acesso em: 28 jan. 2010. doi: 10.1590/50103-31312001000200002.

CUNHA, A.R.; MARTINS, D. Classificação climática para os municípios de Botucatu e São Manuel. Irriga, v.41, p.1-11, 2009 .

DALASTRA, I.M. et al. Épocas de poda na produção de figos verdes 'Roxo de Valinhos' em sistema orgânico na região oeste do Paraná. Revista Brasileira de Fruticultura, v.31, n.2, p.447-453, 2009. Disponível em: <http://www.scielo.br/ s c i e lo.ph p s cript $=$ s ci_arttext \& pid $=$ S $0100-$ $29452009000200019 \& \operatorname{lng}=\mathrm{pt} \& \mathrm{nrm}=\mathrm{iso} \& \mathrm{t} \operatorname{lng}=\mathrm{pt}>$. Acesso em: 07 dez. 2009. doi: 10.1590/S0100-29452009000200019 .

DUCATTI, C. et al. Modelo teórico e experimental da reciclagem do carbono-13 em tecidos de mamíferos e aves. Scientia Agricola, v.59, n.1, p.29-33, 2002. Disponível em: $<$ http://www.scielo.br/scielo.php? script $=$ sci_arttext\&pid= $\mathrm{S} 013=9016200200003 \& \operatorname{lng}=\mathrm{en} \& \mathrm{~nm}=\mathrm{iso} \& \mathrm{t} \operatorname{lng}=\mathrm{pt}>$. Acesso em: 28 jan. 2010. doi: 10.1590/S0103-901620020000100003.
EHLERINGER, J.R.; et al. Stable isotopes and plant carbonwater relations. New York: Academic, 1993. 555p.

EMBRAPA. Centro Nacional. Pesquisas em Solos. Sistema brasileiro de classificação de solos. Brasília: EmbrapaSPI; Rio de Janeiro: Embrapa-Solos, 2006. 306p.

FARQUHAR, G.D. et al. Carbon isotope fractionation and plant water-use efficiency. In: RUNDEL, P.W. et al. (Ed.). Stable isotopes in ecological research. New York: SpringerVerlag New York, 1989. p.21-40.

GIACOBBO, C.L. et al. Cultivo da figueira conduzida em quatro diferentes densidades de plantio. Revista Brasileira Agrociência, v.13, n.1, p.43-46, 2007.

LARCHER, W. Ecofisiologia vegetal. São Carlos: Rima, 2000. p.531.

LEONEL, S; TECCHIO, M.A. Produção de figueira submetida a diferentes épocas de poda e irrigação. Revista Brasileira de Fruticultura, v.30, n.4, p.1015-1021, 2008. Disponível em: $<\mathrm{http}$ ://www.scielo.br/scielo.php?script=sci arttext\&pid=S010029452008000400029\&lng=pt $>$. Acesso em: 28 jan. 2010. doi: 10.1590/S0100-29452008000400029.

MACHADO, E.C. et al. Variação sazonal da fotossíntese, condutância estomática e potencial da água na folha de laranjeira 'Valência'. Scientia Agrícola, v.59, n.1, p.53-58, 2002. Disponível em: $<$ http:/www.scielo.br/scielo.php?script=sci_arttext\&pid=S010390162002000100007\&lng=iso\&tlng=pt $>$. Acesso em: 28 jan. 2010. doi: 10.1590/S0103-90162002000100007.

NOGUEIRA, R.J.M.C. et al. Expressões ecofisiológicas de germoplasma de Hancornia speciosa Gomes cultivado no litoral de Pernambuco. Ciência Rural, v.29, n.4, p.731-732, 1999. Disponível em: <http:/www.scielo.br/scielo.php?script=sci_arttext\&pid=S0103$84781999000400027 \& \operatorname{lng}=$ pt\&nrm $=$ iso \&tlng $=$ pt $>$. Acesso em: 28 jan. 2010. doi: 10.1590/S0103-84781999000400027.

PIMENTEL, C. Metabolismo de carbono na agricultura tropical. Seropédica: Edur, 1998. 150p. 
PIGÉ, L.G. et al. Carbon allocation to volatiles and other reproductive componentsin male Ficus carica (Moraceae). American Journal of Botany, v.88, p.2214-2220, 2001.

SINCLAIR, T.R.; HORIE, T. Crop physiology \& metabolism. Leaf nitrogen, photosynthesis, and crop radiation use efficiency: a review. Crop Science. v. 29, p.90-98, 1989.

TING, I.P. et al. Photosynthesis in hemiephiphytic species of Clusia and Ficus. Oecologia, v.74, p.339-346, 1987.
ZOTZ, G. et al. Water relations and hydraulic architecture of woody hemiepiphytes. Journal of Experimental Botany, v.48, n.10, p.1825-1833, 1997. Disponível em: < http:// http:/ /jxb.oxfordjournals.org/cgi/reprint/48/10/1825>. Acesso em: 10 fev. 2010 . doi: $10.1093 / \mathrm{jxb} / 48.10 .1825$.

WONG, W.; ABRAMS, S.A. Production of stable isotopes for nutrionrelated reserarch. In: ; (Eds). Stable isotopes in human nutrition: laboratory methods and research applications. Cambridge: CABI, 2003. p.5-10. 